Article

\title{
An Information Approach to the Impact of Ethanol Policy on Regional Changes in Corn Production
}

\author{
Charles B. Moss ${ }^{1}$, Dong Hee Suh ${ }^{2}$ and Ashok K. Mishra ${ }^{3}$ \\ University of Florida; cbmoss@ufl.edu \\ Korea University; dhsuh@korea.ac.kr \\ 3 Arizona State University; Ashok.K.Mishra@asu.edu \\ * Correspondence: cbmoss@ufl.edu; Tel.: +1-352-294-7630
}

\begin{abstract}
This paper examines the regional changes of corn production and the relationship between ethanol production and corn production. The underlying hypothesis is that the rapid growth in ethanol production causes regional expansion of corn production outside the traditional regions. This paper introduces the information approach developed by entropy theory to describe these regional changes. The results support the hypothesis that ethanol production leads to expansion of corn production outside traditional corn producing regions.
\end{abstract}

Keywords: corn, ethanol, regional distribution

\section{Introduction}

This paper examines the effect of ethanol policy on the regional distribution of corn production in the United States using the entropy measure developed by Shannon [1]. Ethanol policy in the guise of the renewal of the Volumetric Ethanol Excise Tax Credit (VEETC) continued to be a significant policy debate until January 2012 when it appeared to expire without congressional action. According to the popular press, the VEETC succumbed to high commodity prices and difficult times for the federal budget [2]. However, a tax credit with its origin in the Energy Tax Act of 1978 may not go away quietly, especially given the increased investment in ethanol processing plants in corn producing areas (predominantly in Midwestern states) since 2005. Apart from the investment in ethanol processing facilities, the high real corn prices attributed in part to ethanol policies have contributed to significant changes in agricultural land use in the United States. Most of the attention on land use changes has been on the conversion of environmentally sensitive land into corn production. Pimentel [3, p.6] conjectures that the conversion of these sensitive lands into corn production is particularly troublesome "Ethanol produced from corn causes environmental degradation from increased soil erosion and aquifer mining, from soil, water, and air pollution, and increased emissions of global-warming gases." However, most of these discussions fail to consider the regional dimensions of the changes in land use. Our results indicate that the increased production of ethanol contributed to increased corn production in non-traditional corn areas.

The implications of the effect of bioenergy policies were highlighted by Hertel's [4] presidential address to the American Agricultural Economics Association in 2010. Hertel states that over the next 50 years, the world's agricultural system must support an expected $50 \%$ increase in population over 2010 levels. Complicating this challenge, he conjectures that the rate of productivity change has slowed, especially for staple. Additionally, he points out that

[The] public opposition to genetically modified crops has slowed the application of promising biotechnology developments to food production in some parts of the world. 
At the same time, the growing use of biomass for energy generation has introduced an important new source of industrial demand for agricultural markets [4, p.259].

If the rate of technical change has slowed, the increased demand for all agricultural outputs will have to be met by increasing the resources employed by agriculture. Hertel's conjecture of a perfect storm for agriculture focused on the availability of land and attention to whether the increased demand for output can be most economically met by increasing the acreage (i.e., exploiting the extensive margin) or by applying more inputs on each acre (i.e., exploiting the intensive margin). He assumes that the intensive margin is relatively fixed and sets about an analysis of land available for agriculture worldwide.

Historically, the growth in ethanol production in the United States has been relatively anemic. As described by Tyner [5], ethanol production grew from 430 million gallons in 1984 to 3.4 billion gallons in 2004 a growth rate of about 149 million gallons per year. The rapid growth in ethanol production was led by a dramatic rise in oil prices. This rapid increase in ethanol production increased the corn planted in 2007, reduced the acres of soybeans planted, and, hence, increased the price of soybeans. Aside from the effect on the corn/soybean rotation in the Midwest, the increased corn prices also increased the price of livestock feed which resulted in higher meat prices in the United States. However, the effect of ethanol subsidies on agriculture was not limited to the Midwest. The decoupling provisions of the Federal Agricultural Improvement and Reform Act of 1996, the Farm Security and Rural Investment Act of 2002, and the Food, Conservation and Energy Act of 2008 provided southern farmers the option of planting corn while receiving a portion of the cotton payments [6]. ${ }^{1}$ Given the relatively low cotton prices through the first two decades of the 21st century, several farmers in Arkansas and Mississippi planted corn where cotton was once king. This change implied some increased risk as southern farmers experienced increased incidence of diseases such as Aflatoxin (Aspergillus Flavus), limiting the potential market for their product.

In our analysis of farmer response to ethanol policies, we assume that the supply of outputs and the derived demand for inputs is determined by optimizing decisions, the technology possessed by the firm (which may be a function of local factors such as climate), and a vector of quasi-fixed variables including the quantity of farmland used in production. Mathematically, we define the firm $i$ 's profit following Lau's approach [7]:

$$
\left.\begin{array}{c}
\pi_{i}(p, w)=p^{\prime} y-w^{\prime} x \\
\text { s.t. }\left\{y, x, z_{i}\right\} \in T_{i}
\end{array}\right\} \Rightarrow\left\{\begin{array}{l}
y_{i}^{*}\left(p, w, z_{i}\right) \\
x_{i}^{*}\left(p, w, z_{i}\right)
\end{array}\right.
$$

where $\pi_{i}($.$) is the profit earned by firm i, p$ is the vector of output prices, $y$ is the vector of outputs produced by firm $i, w$ is the vector of input prices, $x$ is the vector of inputs used by firm $i, z_{i}$ is the level of quasi-fixed inputs available to the firm (for our purposes, we consider only farmland), and $T_{i}$ is the firm's production technology. In this formulation the shadow value of farmland is used to allocate farmland across crop alternatives. Thus, as the price of corn increases, the shadow value of land increases and either the level of another crop alternative declines (i.e., the price of corn goes up so the land devoted to cotton is reduced to maximize profit), new land is brought into production (i.e., land from the conservation reserve program is brought back into production), or the price of all alternative crops increase. The overall supply of any crop from state $s$ can then be represented as

$$
y_{s}(p, w)=\sum_{i \in s} y_{i}\left(p, w, z_{i}\right) \ni: \sum_{i \in s} z_{i} \leq z_{s}^{*}
$$

1 Cotton farmers who planted corn still received the Agricultural Marketing Transition Payments (AMTAPs) based on the "buy out" of the deficiency payments, but did not receive the Loan Deficiency Payments when prices fell below the loan rate [6]. 
where $z_{s}^{*}$ is the total cropland available in state $s$. Letting $y_{1 s}(p, w)$ be the quantity of corn produced in state $s$, this paper examines changes in the spatial distribution of the quantity of corn supplied by each state. For this purpose, we will analyze the systematic changes in the entropy measure of this spatial dispersion

\section{Methods and Data}

To analyze the effect of ethanol policy, we examine whether changes in ethanol production, oil prices, and other factors affect the spatial distribution of corn production. In particular, we compute the entropy metric as proposed by Shannon [1] as a measure of this dispersion. The entropy measure is a measure of the relative quantity of information based on the probabilities of a signal. Specifically, if we assume that $N$ possible outcomes are possible, then the relative likelihood (or probability) of each individual event $s=1, \cdots N$ can be denoted $p_{s}$. In our application, the signal will be the probability that any bushel of corn will be produced in state $s$. Empirically, $p_{s}$ is then the share of corn produced in state $s$

$$
p_{s}=\frac{y_{1 s}(p, w)}{\sum_{\tilde{s}} y_{1 \tilde{s}}(p, w)}
$$

Shannon demonstrates that the entropy measure $J$ defined as

$$
J=-\sum_{s=1}^{S} p_{s} \ln \left(p_{s}\right)
$$

measures the amount of information in the signal. Intuitively, as the production of corn is concentrated to a single state $p_{s} \rightarrow 1$ then $p_{r} \rightarrow 0$ for all other states. In this scenario $J \rightarrow 0$ since $-\ln \left(p_{s}\right) \rightarrow 0$ from above and $-p_{r} \ln \left(p_{r}\right) \rightarrow 0$ because $p_{r}$ approaches zero faster than $\ln \left(p_{r}\right)$ approaches $-\infty$. Thus, as corn production concentrates into one state, the entropy measure declines to zero. At the other extreme, as corn production diversifies across state, the measure reaches a maximum of $-(1 / n) \ln (1 / n) \gg 0$.

One of the primary advantages to the entropy measure (and other informational measures used in economics such as Theil's measure of income inequality [8]) is the decomposability of the measure. Specifically, if we assume that the states can be divided into $R$ regions $r \in R$, the total inequality can be reexpressed as

$$
J=-\sum_{s=1}^{S} p_{s} \ln \left(p_{s}\right)=J_{R}+\bar{J}
$$

where $J_{R}$ is the inequality between regions defined as

$$
J_{R}=-\sum_{r \in R} P_{r} \ln \left(P_{r}\right) \ni: P_{r}=\sum_{s \in r} p_{s}
$$

and $\bar{J}$ is the average inequality within each region defined as

$$
\bar{J}=P_{r} J_{r} \ni: J_{r}=-\sum_{s \in r} p_{s} \ln \left(p_{s}\right) .
$$

where $J_{r}$ is the entropy withing region $r$. Thus, in this study we measure the changes in regional production within a region (such as the Corn Belt) in $J_{r}$ and across regions through $J_{R}$.

The data used in this analysis is derived from four sources. First, data on corn production by state as well as the prices of corn and cotton was obtained from the Quickstats website provided by the U.S. Department of Agriculture's National Agricultural Statistics Service. While this data is available for most states from the 1930s, the overall sample was limited to 1982 through 2016 due to the availability of Ethanol production data which was obtained from the U.S. Department of Energy, Information Administration. The Brent Crude price was used as our crude oil price. This data was 
taken from the Federal Reserve Bank of St. Louis's FRED database. Finally, we used the Implicit Price Deflator for Personal Consumption Expenditures from the Bureau of Economic Analysis of the U.S. Department of Commerce to transform the prices to 2016 dollars. Our regional analysis is based on the Economic Research Service's (ERS) ten production regions (which makes some allowances for agronomic similarities). We exclude Connecticut, Maine, Massachusetts, New Hampshire, Nevada, Rhode Island, and Vermont because produce an insignificant quantity of corn. In addition, among the ten, regions we distinguish the traditional regions of corn production from the non-traditional regions.

Table 1 shows the regional separation the Lake States (LS), the Corn Belt (CB), the Northern Plains (NP), and the Appalachian States (AS) are considered the traditional areas of corn production, while the Southeast (SE) and Delta States (DS) are regarded as the non-traditional areas of corn production. The other regions such as the Northeast, the Southern Plains, the Mountain States, and the Pacific States are defined as the rest of the regions of corn production. ${ }^{2}$ We focus on comparing the traditional regions with the non-traditional regions to identify regional changes in the share of corn production. As Table 1 represents corn production of each region, most corn production is mainly achieved in the traditional regions, specifically, in the Corn Belt. However, corn production in the non-traditional regions is even less than that of the traditional regions because the non-traditional regions have historically been better suited to the production of other crops such as cotton, sugarcane, winter vegetables, and soybeans that have made serious inroads into southern agriculture since the 1970s.

Both traditional regions and non-traditional regions are constructed to examine whether changes in the ethanol policy affect the regional inequality of corn production by replacing traditional southern crops with corn production. In this analysis we focus primarily on cotton production in the South. The entropy values for each region capture the inequalities in the share of corn production within and between the regions. Also, ethanol production is used for an appropriate proxy variable for the ethanol subsidy between 1981 and 2016 because ethanol production has increased proportionally to the government expenditure on ethanol tax credits. Corn price, cotton price, and crude oil price are also included to control for possible price effects on the inequality of corn production.

Using ordinary least squares, with entropy values as the dependent variable, we estimate the effect of ethanol policies, cotton prices, and crude oil prices on the spatial dispersion of corn production

$$
J_{t}=\alpha_{0}+\alpha_{1} E_{t}+\sum_{i=1}^{3} \beta_{i} \ln \left(P_{i t}\right)+\epsilon_{t}
$$

where $J_{t}$ is the within-region or between region entropy for year $t, E_{t}$ is the ethanol production in year $t, P_{i t}$ is the price of corn, cotton, and crude oil in year $t$, and $\epsilon_{t}$ is the error term. Given the fact that the entropy measure is typically distributed $\chi^{2}$, the results are then bootstrapped to provide small sample standard errors for the purpose of inference. In addition to providing a robust estimate of the standard errors, the bootstrapped results where also used to construct nonparametric measure of probability. Specifically, the number of times that a parameter changes sign is used as a nonparametric test of statistical significance of any particular regression parameter. This approach is similar to the approach taken by Mishra et al. [9] who analyzed whether the Federal Agricultural Improvement and Reform Act of 1996 affected the spatial distribution of farmland values.

2 The Northeast includes Connecticut, Delaware, Maine, Massachusetts, Maryland, New Hampshire, New Jersey, New York, Pennsylvania, Rhodes Island, and Vermont. The Lake States include Michigan, Minnesota, and Wisconsin. The Corn Belt consists of Illinois, Indiana, Iowa, Missouri, and Ohio, and the Northern Plains are Kansas, Nebraska, North Dakota, and South Dakota. Appalachia includes Kentucky, North Carolina, Tennessee, Virginia, and West Virginia. The Southeast includes Alabama, Florida, Georgia, and South Carolina, and the Delta covers Arkansas, Louisiana, and Mississippi. The Southern Plains are Oklahoma and Texas, and the Mountain States are Arizona, Colorado, Idaho, Montana, Nevada, New Mexico, Utah, and Wyoming. The Pacific States consist California, Oregon, and Washington. 


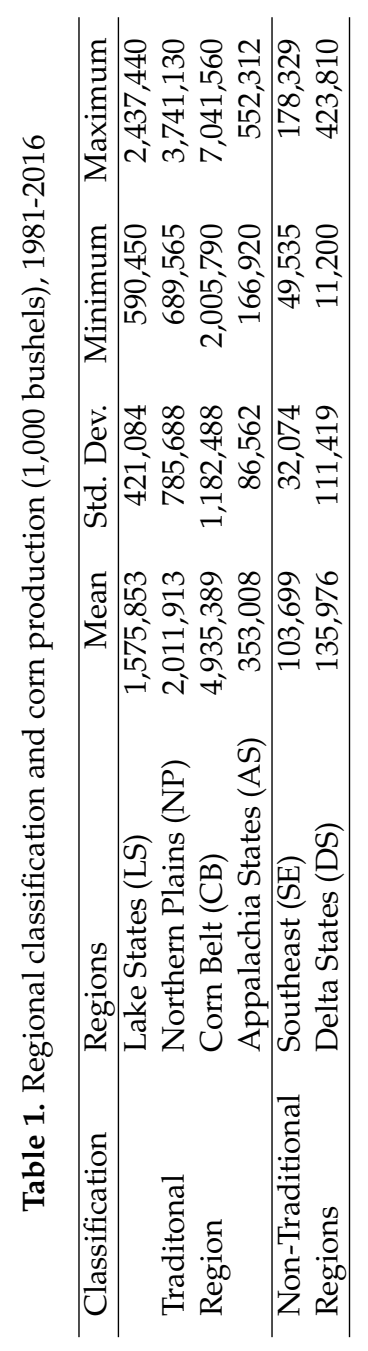




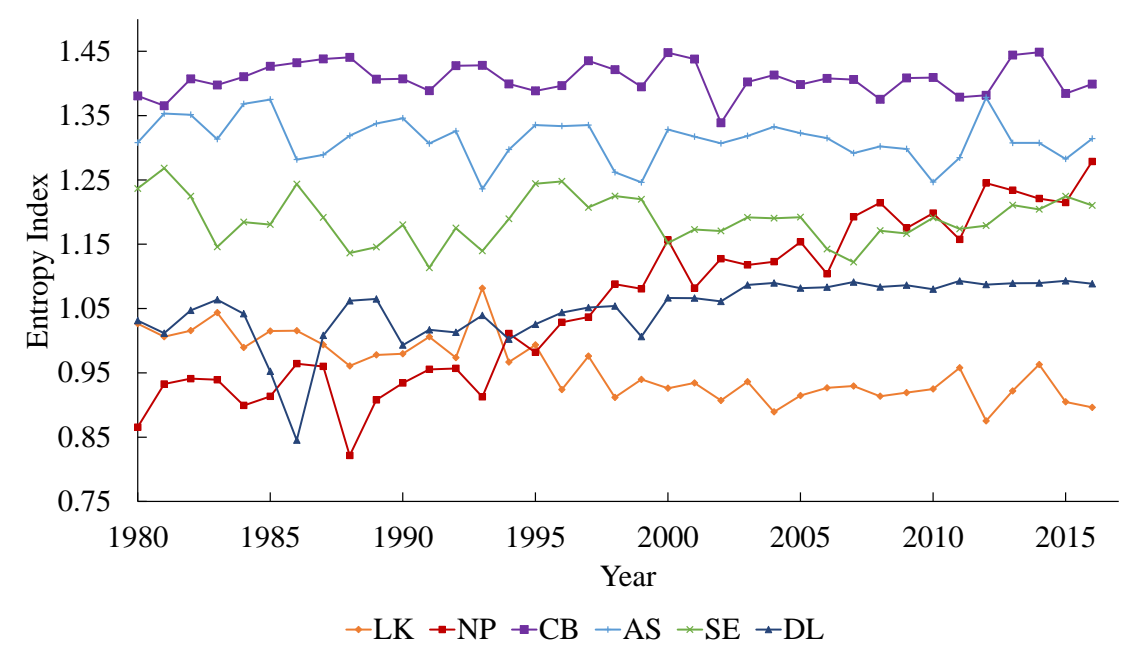

Figure 1. Within-Region Entropy of Traditional and Non-Traditional Regions

\section{Empirical Results}

\subsection{Within-Region Entropy}

Figure 1 depicts the spatial dispersion of corn production for each of the six traditional and non-traditional corn producing regions. The largest entropy measure consistently over time is for the Corn Belt and Appalachian State regions. This numeric result indicates that corn production is fairly uniformly distributed across each of these regions. This is consistent with our concept of the Corn Belt, whose very name implies a collection of states that are known to produce significant quantities of corn. The uniformity of production in the Appalachian States my be a little unexpected. Specifically, the area along the Ohio River in Kentucky is similar to the areas of Illinois, Indiana, and Ohio just across the river. However, several areas of eastern Kentucky are mountainous which inhibits the large scale cultivation of corn. Similarly, the western plains of Tennessee approaching the Mississippi River would be easily cultivated for corn, but cotton may be an extremely viable alternative. In addition, like Kentucky, the eastern part of Tennessee is mountainous. On the other side of the Appalachian States, North Carolina has grown in importance in the production of corn as the confinement feeding of swine and poultry has increased. The difficulties associated with large scale production of corn are endemic to all areas of West Virginia, and Virginia has not been a prominent corn state. Thus, the uniform dispersion of corn production throughout the Appalachian State region may imply that corn production is uniformly a minor crop in each state. The important aspect of our current analysis is that the dispersion of corn production does not appear to change systematically over our time period.

Interestingly, the third-largest entropy measure is for the Southeastern region. Again, the entropy measure implies that the distribution of corn production is similar in each state in the region. Given the states in the region, like the Appalachian States, this may imply that corn is a relatively minor crop in each state. Agronomically, corn does not produce well under excessive heat and humidity. Thus, little corn is produced for grain in Florida. Hence, the northern parts of Alabama, Georgia (except the mountainous regions north and east of Atlanta), and South Carolina have a relatively better climate for corn than the other parts of the Southeast. Corn is planted throughout the region (even in Florida), but may be cut green for silage to be used in dairy operations.

The lowest dispersion in production since 1993 has been in the Lake States. Initially, the corn production in the Northern Plains appeared more concentrated than the Lake States, but after 1993, corn 
The overall decomposition of entropy presented in Equations 5,6, and 7 can be nested. For example, assume that we have eight states $s=1, \cdots 8$ which we divide into two regions $r=1 \Rightarrow s=\{1,2,3,4\}$ and $r=2 \Rightarrow s=\{5,6,7,8\}$. Following Equation 5, we can decompose the inequality in region 1 into the entropy of two different subregions

$$
\left.\begin{array}{l}
\tilde{r}_{1} \Rightarrow s \subset\{1,2\} \\
\tilde{r}_{2} \Rightarrow s \subset\{3,4\}
\end{array}\right\} \ni:\left\{\begin{array}{c}
\tilde{r}_{1} \cup \tilde{r}_{2}=r\{r=1\} \\
\text { and } \tilde{r}_{1} \cap \tilde{r}_{2}=\{\}
\end{array}\right.
$$

Thus, $J_{r}=J_{\tilde{r}}+\bar{J}_{\tilde{r}}$.

production in the Northern Plains has become increasingly uniform across states. The concentration of corn production in the southern parts of the northern regions should have been expected because the relatively short growing season in North Dakota (which is part of the Northern Plains) and Minnesota (which is in the Lake States) implies that crops such as spring wheat may be more viable than corn. In essence, the concentration in these regions should be the inverse of the concentration in Southeast. In the northern regions, the corn is concentrated in a relatively fewer number of states (i.e., Kansas, Nebraska, and South Dakota in the Northern Plains, and Michigan and Wisconsin in the Lake States).

The entropy in the Delta States appears to be relatively constant over time with the exception of a dramatic decline in 1984 and 1985. Overall, the spatial information is in size to the Southeast, but while the Southeast exhibits a slight downward trend the entropy in the Delta States may be slightly increasing over time. This implies that corn production may be becoming more equally distributed. Again, the selection of states may explain this phenomenon. In the Delta States, Arkansas and Mississippi are similar in climate to Alabama, Georgia, and South Carolina while Louisiana is more like Florida in climate. Hence, as Arkansas and Mississippi become more similar, the entropy measure may increase (i.e., if the level of corn produced in Louisiana does not significantly change, entropy will still increase).

There are certain facets of these changes that are consistent with the regional effects of increased ethanol production and other facets that may not support our underlying hypothesis that heightened ethanol production have increased the spatial dispersion of corn production. The increase in concentration of corn production in the Southeast and Lake States supports the intuitive notion that as corn production has become more profitable, those areas in the Southeast and Lake States where corn production is a viable alternative increase their production of corn. Specifically, as corn production becomes more economically viable, farmers plant more corn in northern Alabama, Georgia, and South Carolina in the Southeast, and Michigan and Wisconsin in the Lake States. The potential anomalies are the increased dispersion in the Northern Plains (possibly due to an increase in the production of corn in North Dakota) and the lack of a significant trend in the Delta States.

To provide a more systematic analysis of the entropy over our sample, we apply the regression in Equation 8 to the entropy computations. Consistent with the forgoing discussion, the results presented in Table 2 indicate that the effect of ethanol production on the entropy of corn production is statistically significant in the Lake States, Northern Plains, Appalachia States and Delta States. Consistent with our discussion of the graphical data, increases in ethanol production are associated with increasing concentration of corn production in the Lake States. However, the results also indicate that the increased level of ethanol production has also been associated with increased corn production concentration in the Appalachian States. In addition, the results presented in Table 2 indicate that the increased level of ethanol production is associated with an increased dispersion of corn production in the Northern Plains and the Delta States (although the last result has less statistical support). In addition, the other variables are not statistically significant with the possible exception of the effect of oil prices on the dispersion of corn production in the Northern Plains and Appalachian States.

\subsection{Between-Region Entropy}

Figure 2 presents the inequality between regions within the traditional and non-traditional corn regions ${ }^{3}$. Overall, the within-region entropy for the traditional and non-traditional regions 


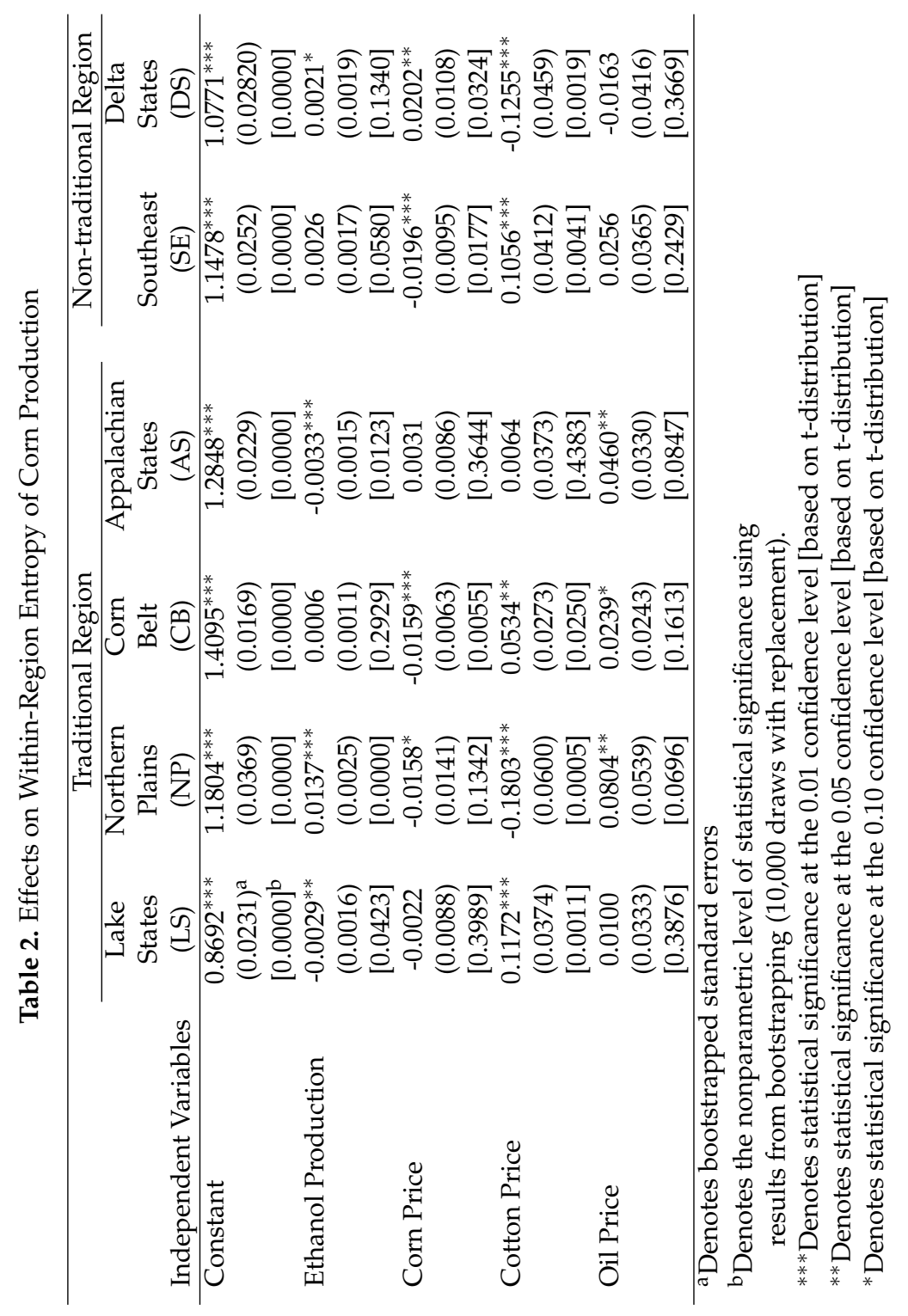




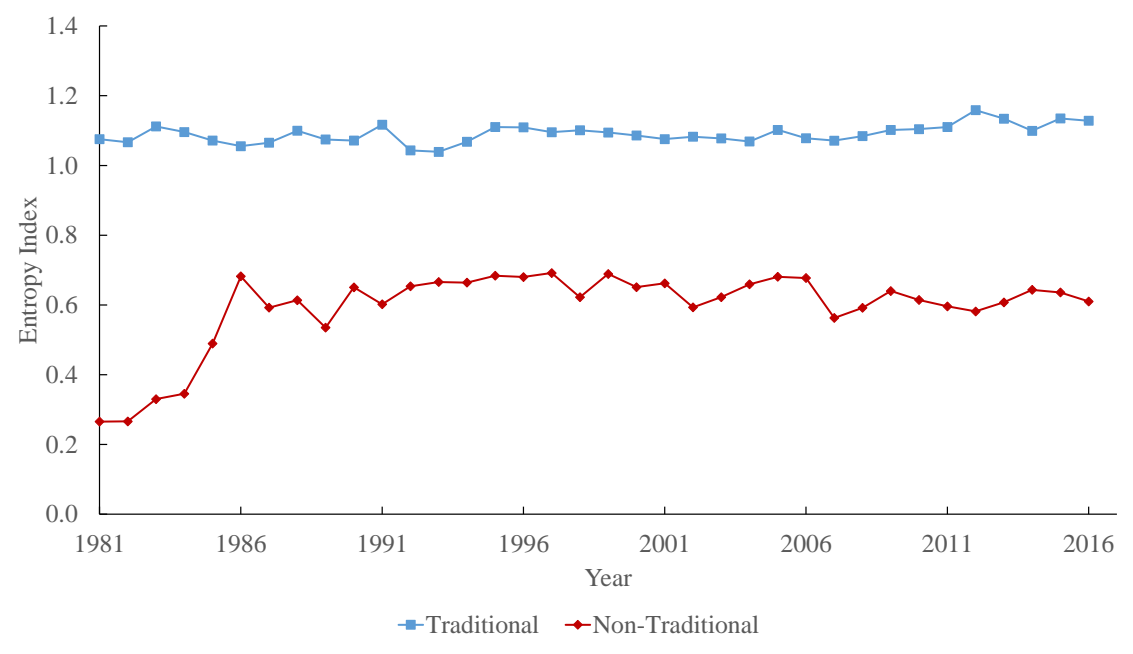

Figure 2. Between-Region Entropy of Traditional and Non-traditional Regions

do not appear to vary systematically over time. The entropy in the traditional corn producing region appears to be very volatile between 1984 and 1994, but the variation appears to be random (without discernible structure). On the other hand, the within region entropy for the non-traditional production region appears to be less volatile and fairly constant over time (neither increasing or decreasing). Thus, we would conclude that changes in ethanol production and/or ethanol policy has not systematically affected the geographical distribution of corn production within each region (that is, between traditional corn growing regions as one group and non-traditional corn growing regions as a second group).

The empirical results from estimation of Equation 8 using the within-region entropy for the traditional and non-traditional corn growing areas as dependent variables are consistent with the graphical discussion. Ethanol production appears to be significant in explaining the geographical dispersion for corn production in the traditional and non-traditional corn growing region at the 0.01 level of statistical significance. Thus, the results indicate some statistical evidence exists that the increased production of ethanol has increased the dispersion of corn production across both the traditional and non-traditional production regions. In addition, there is some evidence that the changes in corn prices have also contributed to this increase in dispersion across traditional regions (as evidenced by the fact that the estimated coefficient on corn prices is positive and statistically significant at the 0.05 level of confidence). However, an increase in corn prices appear to increase the concentration of corn production in non-traditional regions. Specifically, the estimated parameter for corn prices is negative and statistically significant at the 0.10 level of confidence under the assumptions of normality (i.e., for the $t$-distribution). This finding is not robust to the assumption of normality (i.e., the nonparametric confidence level increases to 0.1295).

\subsection{Aggregate Entropy}

Finally, Figure 3 presents the results for the overall entropy of corn production over time. The overall entropy measure has the greatest overall volatility, but really does not appear to possess an apparent trend. Like the entropy for the traditional region presented in Figure 2, the overall entropy shows the most volatility between 1984 and 1994. The average within entropy has a somewhat distinct upward trend indicating that the overall dispersion within each region appears to be increasing. Thus, on average, corn production is becoming more dispersed within each region (i.e., the states within the 
Table 3. Effects on Between-Region Entropy of Corn Production

\begin{tabular}{|c|c|c|}
\hline Independent & Traditional & Non-Traditional \\
\hline Variables & Region & Region \\
\hline \multirow[t]{3}{*}{ Constant } & $1.0651^{* * *}$ & $0.8800^{* * *}$ \\
\hline & $(0.0144)^{\mathrm{a}}$ & $(0.0553)$ \\
\hline & {$[0.0000]^{b}$} & [0.0000] \\
\hline \multirow[t]{3}{*}{ Ethanol Production } & $0.0035^{* * *}$ & $0.0097^{* * *}$ \\
\hline & $(0.0009)$ & $(0.0036)$ \\
\hline & {$[0.0001]$} & {$[0.0027]$} \\
\hline \multirow[t]{3}{*}{ Corn Price } & $0.0118^{* * *}$ & $-0.0230^{*}$ \\
\hline & $(0.0054)$ & $(0.0204)$ \\
\hline & {$[0.0134]$} & [0.1295] \\
\hline \multirow[t]{3}{*}{ Cotton Price } & -0.0174 & $-0.1578^{* *}$ \\
\hline & $(0.0233)$ & $(0.0886)$ \\
\hline & {$[0.2308]$} & [0.0402] \\
\hline \multirow[t]{3}{*}{ Oil Price } & $-0.0414^{* *}$ & $-0.1823^{* * *}$ \\
\hline & $(0.0205)$ & $(0.0777)$ \\
\hline & [0.0195] & [0.0092] \\
\hline \multicolumn{3}{|c|}{${ }^{\mathrm{a}}$ Denotes bootstrapped standard errors } \\
\hline \multicolumn{3}{|c|}{$\begin{array}{l}{ }^{b} \text { Denotes the nonparametric level of statistical significance using } \\
\text { results from bootstrapping (10,000 draws with replacement). }\end{array}$} \\
\hline \multicolumn{3}{|c|}{ *** Denotes statistical significance at the 0.01 confidence level [based on t-distribution] } \\
\hline \multicolumn{3}{|c|}{${ }^{* *}$ Denotes statistical significance at the 0.05 confidence level [based on $\mathrm{t}$-distribution] } \\
\hline${ }^{*}$ Denotes statistical s & nificance at & e level [based on t-distribution] \\
\hline
\end{tabular}

Corn Belt, the Lake States, etc. are becoming more alike on average). Like the overall spatial measure of dispersion, the volatility in the between-region entropy obscures any readily discernible pattern over time.

Table 4 presents the results for Equation 8 using the aggregate entropy measures as the dependent variables. Focusing on the between-region entropy measure first, increases in corn prices are associated with more equality between regions at the 0.01 level of statistical significance. In essence, increases in corn prices are associated with increased equality between traditional and non-traditional corn production regions. In the context of land use, increases in corn prices leads to more corn being harvested in non-traditional corn producing regions (such as the Delta States or the Southeast). Turning to the within-region results, the coefficient on ethanol production is statistically significant at the 0.01 level of confidence. Thus, because the coefficient is positive, increased ethanol production is associated with a more equal distribution of corn production within each region (or more appropriately between states within the average region). Finally, the results for total entropy show weak support for both factors (i.e., both the level of ethanol production and the corn price are associated with more dispersion in aggregate).

\section{Discussion and Implications}

This study examines the effect of ethanol production on the spatial distribution of corn production using the entropy measure proposed by Shannon [1]. The results indicate increases in ethanol production affects the distribution of corn production between states by concentrating the corn production in the Lake States and the Appalachian States and increasing the dispersion in the Northern Plains and the Delta States. These changes are important for different regions. The increased concentration in the Lake States and Appalachian States indicates an increased amount of corn being produced in a band of farmland suited to corn production. Looking at the individual regions, the increased regionalization in the Lake States may be associated with the investment in several ethanol production facilities in Minnesota. 


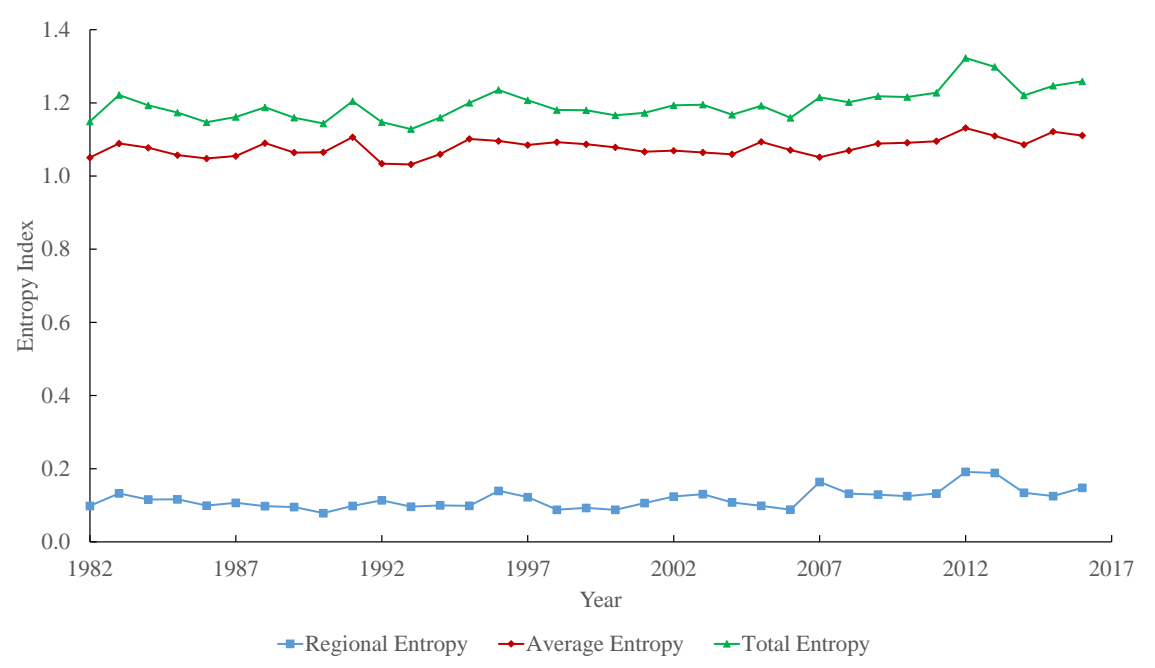

Figure 3. Aggregate Entropy of Corn Production

Table 4. Effects on Aggregate Entropy of Corn Production

\begin{tabular}{lccc}
\hline Independent & Between-Region & Average Within-Region & Total \\
Variables & Entropy & Entropy & $1.1526^{* * *}$ \\
\hline Constant & $0.0888^{* * *}$ & $1.0638^{* * *}$ & $(0.0196)$ \\
& $(0.0135)^{\mathrm{a}}$ & $(0.0136)$ & {$[0.0000]$} \\
& {$[0.0000]^{\mathrm{b}}$} & {$[0.0000]$} & $0.0055^{* * *}$ \\
Ethanol Production & $0.0022^{* * *}$ & $0.0033^{* * *}$ & $(0.0013)$ \\
& $(0.0009)$ & $(0.0009)$ & {$[0.0000]$} \\
Corn Price & {$[0.0050]$} & {$[0.0000]$} & $0.0186^{* * *}$ \\
& $0.0093^{* *}$ & $0.0093^{* *}$ & $(0.0075)$ \\
Cotton Price & $(0.0051)$ & $(0.0051)$ & {$[0.0056]$} \\
& {$[0.0357]$} & {$[0.0340]$} & $-0.0390^{*}$ \\
& $-0.0225^{*}$ & -0.0165 & $(0.0319)$ \\
Oil Price & $(0.0220)$ & $(0.0222)$ & {$[0.1168]$} \\
& {$[0.1605]$} & {$[0.2281]$} & $-0.0438^{* *}$ \\
& 0.0007 & $-0.0445^{* * *}$ & $(0.0288)$ \\
& $(0.0194)$ & $(0.0197)$ & {$[0.0668]$} \\
\hline
\end{tabular}

${ }^{a}$ Denotes bootstrapped standard errors

${ }^{b}$ Denotes the nonparametric level of statistical significance using results from bootstrapping (10,000 draws with replacement).

*** Denotes statistical significance at the 0.01 confidence level [based on $\mathrm{t}$-distribution]

** Denotes statistical significance at the 0.05 confidence level [based on t-distribution]

*Denotes statistical significance at the 0.10 confidence level [based on t-distribution] 
The results of our analysis indicate that increases in corn prices have contributed to an increased parity between traditional and non-traditional corn production regions. Similarly, increased ethanol production has been associated with an increased parity on average within each region. Hence, both results support the hypothesis that ethanol production and the associated ethanol policies have contributed to changes in land use. Specifically, changes in ethanol production have contributed to the increased production of corn outside traditional corn producing regions.

The dichotomy between the effect of corn prices and ethanol production is somewhat interesting. Intuitively, we would anticipate the production in ethanol and corn prices to be positively correlated more ethanol production should imply increased corn prices. However, each factor appears to operate differently. Changes in ethanol production appears to operate within a region. This suggests that ethanol plants have been built in marginally producing regions of traditional corn-producing states. In contrast, a new ethanol plant may not be built outside a traditional corn region (such as southern Arkansas). However, farmers in that region may plant corn in response to higher corn prices which result, in part, from increased ethanol production.

Hence, our results indicate that Pimentel's [3] conjecture that ethanol subsidies will have a detrimental effect on the environment by encouraging producers to bring marginal (more fragile) land into production is probably correct, but incomplete. Specifically, the increased corn price may pull marginal land into production, but it also increases corn plantings in non-traditional corn areas. The net environmental effect is then dependent on the environmental attributes of the crops being supplanted for the increase in corn production. In the South, it is likely that cotton is being replaced by corn. While a more complete analysis is required, cotton typically requires more pesticides and herbicides than corn production, so the net environmental impact may be positive. More information on the change in the portfolio of crops may be possible by extending the current results using the inequality of components approach presented in Theil and Moss [10].

2

1. Shannon, C.E. A mathematical theory of communication. Bell System Technical Journal 1948, 27, 379-423.

2. Pearson, R. After Three Decades, Tax Credit for Ethanol Expires. New York Times, 2012.

3. Pimentel, D. Ethanol Fuels: Energy Security, Economics, and the Environment. Journal of Agricultural and Environmental Ethics 1991, 4, 1-13.

4. Hertel, T. The Global Supply and Demand for Agricultural Land in 2050: A Perfect Storm in the Making? American Journal of Agricultural Economics 2011, 93, 259-275.

5. Tyner, W. The U.S. Ethanol and Biofuels Boom: Its Origins, Current Status, and Future Prospects. BioScience 2008, 58, 646-653.

6. Schmitz, A.; Moss, C.B.; Schmitz, T.G.; Furtan, H.W.; Schmitz, H.C. Agricultural Policy, Agribusiness, and Rent-Seeking Behaviour; University of Toronto Press, 2010.

7. Lau, L.J. A Characterization of the Normalized Restricted Profit Function. Journal of Economic Theory 1976, 12, 131-163.

8. Theil, H. Economics and Information Theory; North-Holland Publishing Co., 1967.

9. Mishra, A.; Livanis, G.; Moss, C. Did the Federal Agricultural Improvement and Reform Act of 1996 Affect Farmland Values. Entropy 2011, 13, 668-682.

10. Theil, H.; Moss, C. The Measurement of Inequality by Components of Total Expenditure. Empirical Economics 1999, 24, 559-561. 